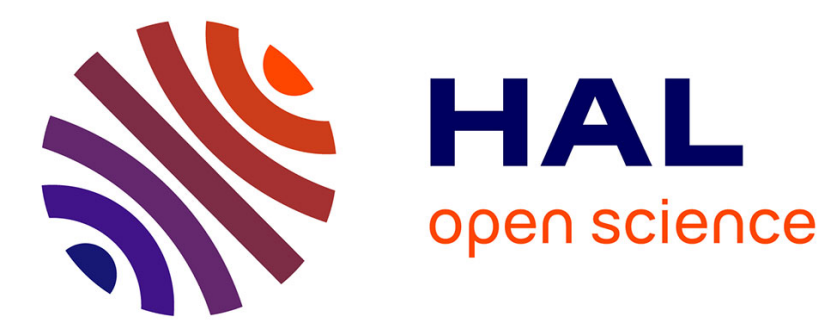

\title{
LASER-INDUCED DECOMPOSITION OF METAL CARBONYLS FOR CHEMICAL VAPOR DEPOSITION OF MICROSTRUCTURES
}

\author{
D. Tonneau, G. Auvert, Y. Pauleau
}

\section{> To cite this version:}

D. Tonneau, G. Auvert, Y. Pauleau. LASER-INDUCED DECOMPOSITION OF METAL CARBONYLS FOR CHEMICAL VAPOR DEPOSITION OF MICROSTRUCTURES. Journal de Physique Colloques, 1989, 50 (C5), pp.C5-647-C5-656. 10.1051/jphyscol:1989575 . jpa-00229608

\section{HAL Id: jpa-00229608 https://hal.science/jpa-00229608}

Submitted on 1 Jan 1989

HAL is a multi-disciplinary open access archive for the deposit and dissemination of scientific research documents, whether they are published or not. The documents may come from teaching and research institutions in France or abroad, or from public or private research centers.
L'archive ouverte pluridisciplinaire HAL, est destinée au dépôt et à la diffusion de documents scientifiques de niveau recherche, publiés ou non, émanant des établissements d'enseignement et de recherche français ou étrangers, des laboratoires publics ou privés. 
JOURNAL DE PHYSIQUE

Colloque C5, supplément au $n^{\circ} 5$, Tome 50, mai 1989

LASER-INDUCED DECOMPOSITION OF METAL CARBONYLS FOR CHEMICAL VAPOR DEPOSITION OF MICROSTRUCTURES

\author{
D. TONNEAU* , G. AUVERT and Y. PAULEAU \\ Centre National d'Etudes des Télécommunications, BP. 98, F-38243, \\ Meylan, France \\ * Société Bertin, BP. 22, F-13762 Les Milles, France
}

Résumé - La cinétique de dépôt de microstructures métalliques obtenues par décomposition de tungstène et nickel carbonyles sous irradiation laser a été étudiée en fonction de la durée d'irradiation, de la puissance du faisceau laser et de la pression du gaz réactif. La vitesse de dépôt des microstructures obtenues à partir de $W(C O)_{6}$ sur des substrats de silicium chauffés par un faisceau laser argon ionisé continu est faible (10 à $30 \mathrm{~nm} / \mathrm{s}$ ) même au-dessus de $900^{\circ} \mathrm{C}$. Le dépôt de microstructures de. nickel entre 200 et $400^{\circ} \mathrm{C}$ à partir de $\mathrm{Ni}(\mathrm{CO})_{4}$ sur substrats de quartz chauffés par un faisceau laser $\mathrm{CO}_{2} \mathrm{continu}$ nécessite des puissances laser relativement élevées à cause de la forte réflectivité du métal à $10.59 \mathrm{\mu m}$. La vitesse de dépôt du nickel sur silicium irradié par un faisceau laser argon ionisé continu à relativement faible puissance est de l'ordre de quelques $\mu \mathrm{m} / \mathrm{s}$ entre 200 et $400^{\circ} \mathrm{C}$. Le dépôt du métal sous irradiation laser visible ou infrarouge a lieu uniquement par décomposition thermique de $\mathrm{Ni}(\mathrm{CO})_{4}$. La cinétique de dépôt est limitée par la désorption des molécules de $\mathrm{CO}$.

\begin{abstract}
Tungsten and nickel carbonyls were used to produce metal microstructures by laser-induced chemical vapor deposition (CVD) on various substrates. The deposition rate of microstructures produced by thermodecomposition of $W(\mathrm{CO})_{6}$ on Si substrates heated with a $\mathrm{CW} \mathrm{Ar}{ }^{+}$laser beam was relatively low (10 to $30 \mathrm{~nm} / \mathrm{s}$ ) even at high temperatures (above $900^{\circ} \mathrm{C}$ ). Ni microstructures were deposited on quartz substrates irradiated with a $\mathrm{CO}_{2}$ laser beam. Relatively high laser powers were needed to heat the Ni surface up to $400^{\circ} \mathrm{C}$ due to the high reflectivity of the metal at $10.59 \mu \mathrm{m}$. The $\mathrm{Ar}^{+}$laser-induced CVD of $\mathrm{Ni}$ dots on $\mathrm{Si}$ substrates was accomplished with relatively low laser powers; the deposition rate was several $\mu \mathrm{m} / \mathrm{s}$ at low temperatures $\left(200^{\circ}-400^{\circ} \mathrm{C}\right)$. Visible and infrared laser-induced CVD of $\mathrm{Ni}$ microstructures was demonstrated to occur via a purely thermal decomposition of $\mathrm{Ni}(\mathrm{CO})_{4}$. The deposition kinetics + s limited by the desorption of $\mathrm{CO}$ molecules from the $\mathrm{Ni}$ surface.
\end{abstract}

\title{
1 - INTRODUCTION
}

Tungsten and nickel films can be deposited on various substrates by decomposition of carbonyl compounds, $\mathrm{W}(\mathrm{CO})_{6}$ and $\mathrm{Ni}(\mathrm{CO})_{4}$, below $500^{\circ} \mathrm{C} / 1,2 /$. These deposition processes are very attractive for producing thin films of $\mathrm{W}$ and $\mathrm{Ni}$ on temperature sensitive substrates such as semiconductor substrates. During the last few years, laser-induced chemical vapor deposition (LCVD) processes have received considerable attention in the microelectronics industry. Direct-write metalization of integrated circuits using LCVD of microstructures offers notable advantages including local deposition confined to micron size areas, high deposition rates and maskless processes. This technique can be used for the repair of defects in photomasks and the rewiring of conductor lines in integrated circuits $/ 3,4 /$.

Localized deposition of $W$ films has been performed by decomposition of $W(C 0)_{6}$ on substrates irradiated with $\mathrm{cW} / 5-7 /$ or pulsed /8,9/ UV lasers. As $W(\mathrm{CO})_{6}$ exhibits a strong absorption in the UV region, $W$ films were grown at low temperatures by photolysis of the gaseous precursor. Pyrolytic decomposition of $W(\mathrm{CO})_{6}$ on nucleation sites formed on quartz plates has been accomplished by $\mathrm{CW} \mathrm{Ar}{ }^{+}$laser irradiation of the transparent substrates and the effects of the nucleation layer on LCVD of $W$ films have been investigated in detail /10/. Recently, the feasibility of LCVD of $\mathrm{Ni}$ films from $\mathrm{Ni}(\mathrm{CO})_{4}$ has been clearly demonstrated. $\mathrm{SiO}_{2}$ or $\mathrm{Si}$ substrates were irradiated either with a $\mathrm{cW} \mathrm{CO}_{2}^{4}$ laser operating at $10.59 \mu \mathrm{m} / 11-14 /$ or with visible lasers, i.e., a $\mathrm{cW} \mathrm{KI}{ }^{+}$laser tuned at $530.9 \mathrm{~nm} / 15-17 /$ and a $\mathrm{cW} \mathrm{Ar}^{+}$laser tuned at $514.5 \mathrm{~nm} / 18,19 \%$. In fact, the deposition kinetics of $W$ and $\mathrm{Ni}$ films produced by LCVD was not thoroughly investigated and the deposition mechanisms of these metallic microstructures remains essentially unknown.

The purpose of the present work is to produce $W$ and $\mathrm{Ni}$ microstructures by thermal decomposition of volatile metal carbonyls on substrates heated with a laser beam. The rate of thermally-activated reactions depends non linearly on the surface temperature via the Arrhenius factor $\left(k_{0} \times \mathrm{e}^{-\mathrm{E} / \mathrm{RT}}\right)$. This non linearity can enable features finer than the laser beam width to 
be written since the thermodecomposition only occurs at the center of the laser spot. This confinement of the deposition process appears as a decisive advantage of the laser-induced thermodeposition over a photolytic deposition process promoted by UV laser irradiation of the gaseous precursor. The major results on the deposition kinetics of $W$ and $N i$ microstructures on $\mathrm{Si}$ or $\mathrm{SiO}_{2}$ substrates heated with a focused $\mathrm{CW} \mathrm{Ar}^{+}$or $\mathrm{CO}_{2}$ laser beam are reported and the deposition mechanisms are discussed.

\section{2 - EXPERIMENTAL METHOD}

\section{2 - 1 - Experimental procedure}

The experimental arrangement and major characteristics of the procedure used for LCVD of $W$ and $\mathrm{Ni}$ microstructures have been described in a previous paper $/ 20 /$. Quartz plates of $1 \mu \mathrm{m}$ in thickness having one side coated with a $1 \mu \mathrm{m}$ thick $\mathrm{Si} \mathrm{film}$ deposited by sputttering and uncoated quartz plates were used as substrates. The Si coatings were thick enough for total absorption of the visible laser light in these layers. The $\mathrm{Ar}^{+}$and $\mathrm{CO}_{2}$ laser spot diameter on the substrate surface was about 200 and $300 \mu \mathrm{m}$, respectively. The position on the substrate surface was fixed for a given irradiation time ( 1 to $15 \mathrm{~s}$ ) determined by switching on and off the laser beam with a mechanical shutter. The microstructures formed in the hot spot were large enough for characterization by profilometer measurements.

$W$ dots were deposited on Si-coated quartz plates irradiated with a multiline $\mathrm{cW} \mathrm{Ar} \mathrm{Ar}^{+}$laser operating in the range of 488 to $514 \mathrm{~nm}$. The output laser power was varied between 0.2 and $3 \mathrm{~W}$. Solid $\mathrm{W}(\mathrm{CO})_{6}$. was placed in the reaction chamber at room temperature. Under these conditions, the saturation vapor pressure of $W(\mathrm{CO})_{6}$ is $20 \mathrm{mTorr} / 1 /$. In fact, during laser irradiation, the carbonyl vapor pressure was less than $10 \mathrm{mTorr}$ (detection limit of the capacitance gauge).

$\mathrm{Ni}$ dots were produced by decomposition of $\mathrm{Ni}(\mathrm{CO})_{4}$ on uncoated quartz substrates irradiated with a $\mathrm{CW} \mathrm{CO}_{2}$ laser tuned at $10.59 \mu \mathrm{m}$ as well as on $\mathrm{Si}$-coated quartz plates irradiated with the $\mathrm{cW}$ $\mathrm{Ar}^{+}$laser. The pressure of $\mathrm{Ni}(\mathrm{CO})_{4}$ was maintained below 10 Torr to avoid deposition of carbonaceous residues. To elucidate the role of photons in the visible laser-induced CVD process, the $\mathrm{Si}$ coating acting as a substrate was irradiated using two types of configuration : (i) the $\mathrm{cw} \mathrm{Ar}^{+}$laser beam was focused directly on the surface of the Si coating (front irradiation), (ii) in another series of experiments, the laser beam penetrated through the transparent quartz plate before absorption in the Si coating (back irradiation). During the back irradiation of the si-coated quartz plates, the quartz surface remained at room temperature and the deposition of $\mathrm{Ni}$ on quartz was never observed. The back irradiation offers at least two advantages, namely : (i) the absence of any interaction between photons and reactive species excluding any photolytic effect on the deposition process, (ii) a guaranteed isothermal deposition process at a given output laser power since the reflectivity of the irradiated sample, i.e., the quartz/Si coating interface did not vary during the LCVD process.

2 - 2 - Determination of the laser-induced surface temperature

The dominant parameter in the deposition kinetics of metals was expected to be the laser-induced surface temperature. This temperature, determined by solving the heat-diffusion equation using the finite element method $/ 21,22 /$, was found to be linearly dependent on the output laser power. To establish the relationship between the laser-induced surface temperature and the laser power, the value of the laser power, $P_{L} m$, required for melting the $S i$ coating on quartz, i.e., for a surface temperature of $1410^{\circ} \mathrm{C}$, was measured. With the back irradiation (B) of Si-coated quartz plates, the laser-induced surface temperature, $T_{B}$, is expressed as a function of the laser power, $P_{\mathrm{BL}}$, by the following equation :

$$
T_{B}=(1410-20)\left(P_{B L} / P_{B L}{ }^{m}\right)+20
$$

Using the front irradiation (F), the laser-induced surface temperature depends on the surface reflectivity of the samples and is given by :

$$
T_{F}=(1410-20)\left(P_{F L} / P_{B L}{ }^{m}\right)\left(R_{B} / R_{F}\right)+20
$$

where $R_{B}$ is the reflectivity of the $S i$ coating irradiated with the visible laser beam penetrating through the transparent quartz plate, and $R_{F}$ the reflectivity of the $S i$ coating directly irradiated with the laser beam.

During LCVD of metals, the laser-induced surface temperature, $T_{F D}$, or the deposition temperature is given by a similar expression in which $R_{F}$ is replaced by $R_{S}$, the surface reflectivity of the deposited material :

$$
T_{F D}=(1410-20)\left(P_{F L} / P_{B L}{ }^{m}\right)\left(R_{B} / R_{S}\right)+20
$$

The surface reflectivity of $\mathrm{W}$ and $\mathrm{Ni}$ films was measured with a microreflectometer $/ 23 /$. For the visible laser light, the reflectivity of $\mathrm{Si}$ and $\mathrm{Ni}$ was 0.38 and 0.48 , respectively. 
The deposition temperature of $\mathrm{Ni}$ microstructures on uncoated quartz plates irradiated with the $\mathrm{CW} \mathrm{CO}_{2}$ laser beam was evaluated by determining the laser power, $\mathrm{pm}^{\mathrm{m}}$, required for $\mathrm{SiO}_{2}$ melting. Since the irradiation times used in our experiments were very short, the optical damage of substrates which may result from the softening and reflow of the glass substrates was negligible. Accordingly, the optical damage of substrates observable by optical microscopy after laser irradiation was assumed to result only from the melting of the $\mathrm{SiO}_{2}$ substrates. The melting point of these very pure $\mathrm{SiO}_{2}$ substrates was considered to be around $1700^{\circ} \mathrm{C}$ which is the melting point of crystalline silica, cristobalite or tridymite $\mathrm{SiO}_{2} / 24 / . \mathrm{The} \mathrm{CO}_{2}$ laser-induced surface temperature is given as a function of laser power, $P$, by the following expression :

$$
T_{\text {quartz }}=(1700-20)\left(P / P^{m}\right)+20
$$

The surface temperature during LCVD of $\mathrm{Ni}$ microstructures is given by :

$$
T_{N i}=(1700-20)\left(P / P^{m}\right)\left(R_{\text {quartz }} / R_{N i}\right)+20
$$

The reflectivity ratio, $R_{\text {quart }} / R_{N i}$, was determined to be $1 / 5$; therefore:

$$
T_{N i}=(1700-20)\left(P / P^{m}\right)(1 / 5)+20
$$

3 - RESULTS

3 - 1 - Decomposition of W(CO) 6 on Si-coated quartz plates irradiated with the visible laser beam

Dot-shaped microstructures with a shiny surface were deposited from $W(\mathrm{CO})_{6}$ at a pressure below $10 \mathrm{mTorr}$ with a laser power ranging from 1 to $1.6 \mathrm{~W}$; the laser-induced surface temperature was in the range of $900^{\circ}$ to $1300^{\circ} \mathrm{C}$. Carbonaceous deposits were observed on the periphery of the zone of $(0.5 \times 0.7) \mathrm{cm}^{2}$ containing several microstructures. The deposited material was not fully characterized and only preliminary data were obtained. The height of dots determined by profilometer measurements was investigated as a function of irradiation time and laser power.

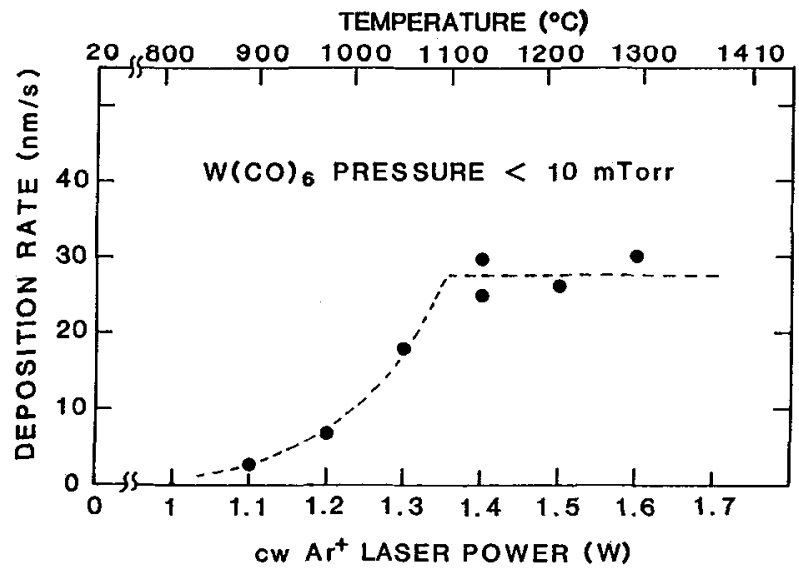

Fig. 1 - Deposition rate of microstructures by $\mathrm{cW} \mathrm{Ar}^{+}$laser-induced decomposition of $W(\mathrm{CO})_{6}$.

The dependence of the height of these dots on irradiation time was found to be linear. The profile of microstructures was Gaussian at deposition temperatures below $1100^{\circ} \mathrm{C}$ and almost rectangular at higher temperatures. The growth rate of these dots versus laser power is given in Fig.l. An increase in the growth rate of Gaussian dots was observed to be approximately exponential between $900^{\circ}$ and $1100^{\circ} \mathrm{C}$. Above this temperature, the growth rate of flat-topped dots was independent of the laser power or laser-induced surface temperature.

\section{$3-2$ - Decomposition of $\left.\mathrm{Ni}_{(\mathrm{CO}}\right)_{4}$ on quartz plates irradiated with the infrared laser beam}

In a series of experiments, the laser-induced decomposition of $\mathrm{Ni}(\mathrm{CO})_{4}$ was carried out for fixed irradiation times (2 or $4 \mathrm{~s}$ ) with laser powers and $\mathrm{Ni}(\mathrm{CO})_{4}$ pressures varying from 0.2 to $1.2 \mathrm{~W}$ and from 2 to 10 . Torr, respectively. Below $0.8 \mathrm{~W}$, flat-topped dots with an almost rectangular profile were deposited (Fig.2). The height of these cylindrical or "pancake" like dots was about $0.2 \mu \mathrm{m}$ and was essentially independent of the laser power, irradiation time and reactant pressure. Only the dot diameter increased with increasing laser power. Above $0.8 \mathrm{~W}$, 


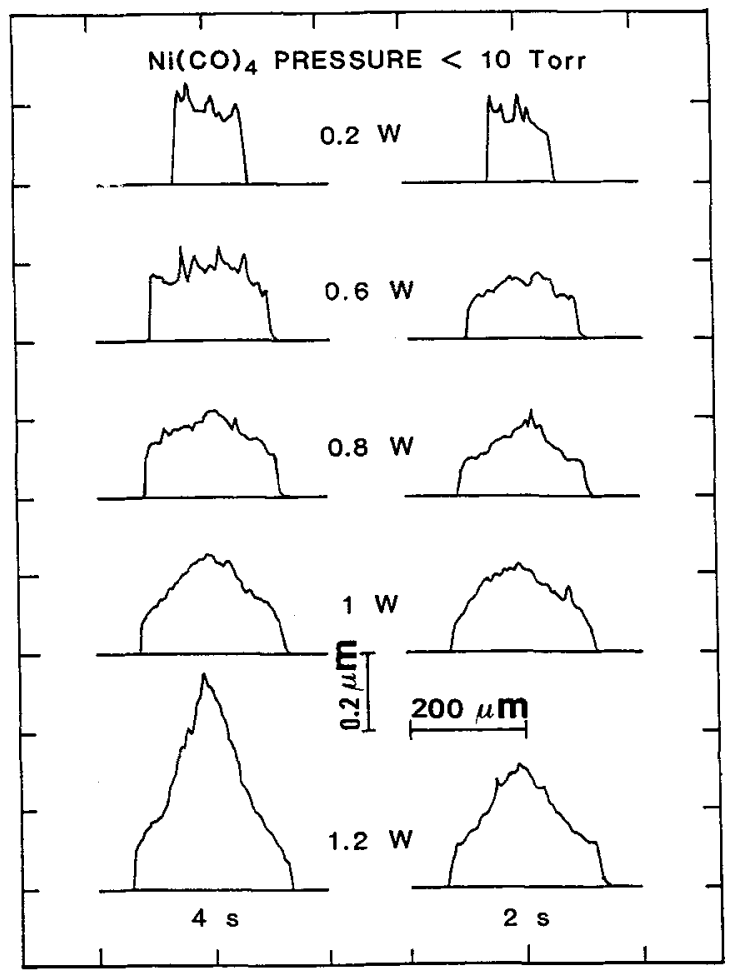

Fig.2 - Typical profiles of microstructures produced by $\mathrm{CW} \mathrm{CO}_{2}$ laser-induced decomposition of $\mathrm{Ni}(\mathrm{CO})_{4} \cdot$

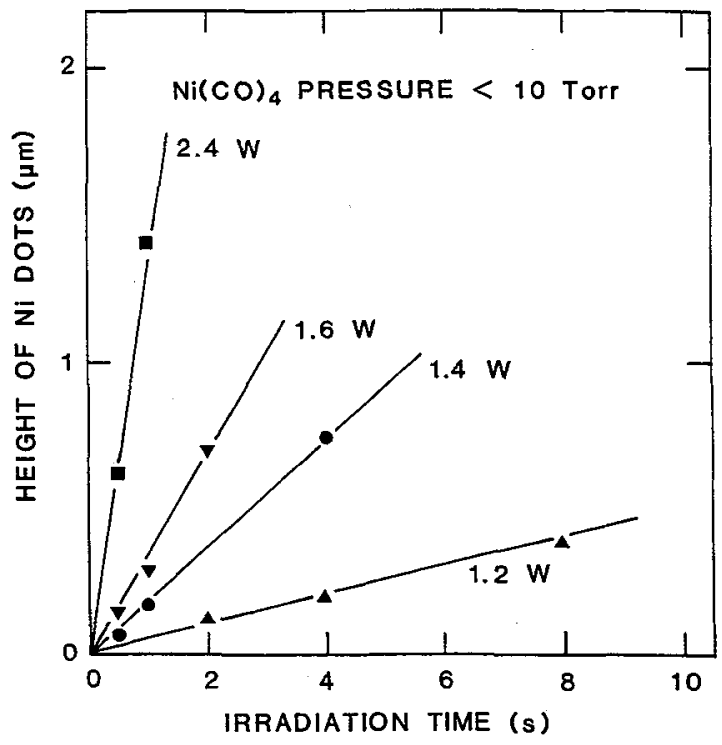

Fig. 3 - Height of $\mathrm{Ni}$ dots versus irradiation time for various $\mathrm{cw} \mathrm{CO}_{2}$ laser powers.

the height of dots increased with increasing irradiation time and laser power. In fact, these microstructures were constituted by a dot with a Gaussian profile put on a $0.2 \mu \mathrm{m}$ thick cylindrical base. 


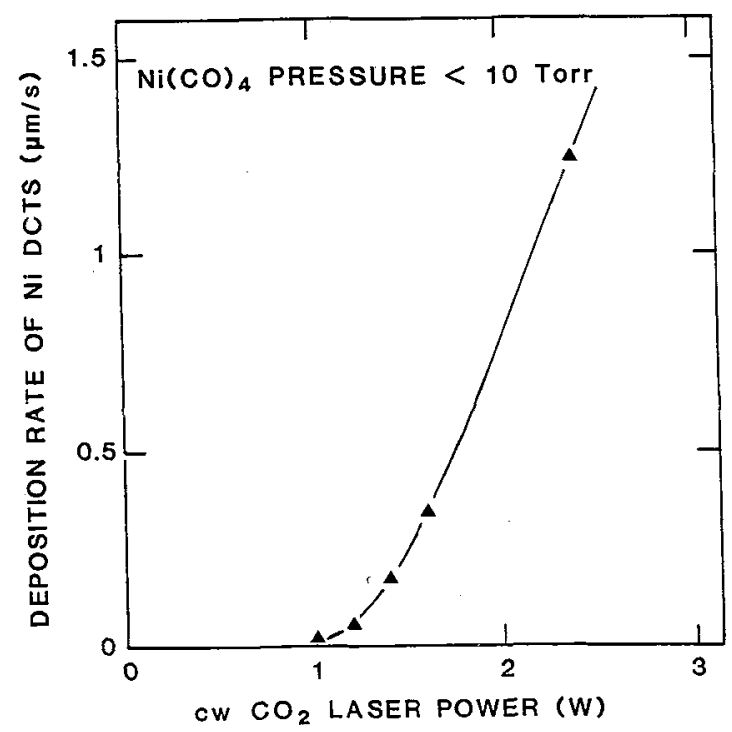

Fig.4 - $\mathrm{cw} \mathrm{CO}_{2}$ laser power effect on deposition rate of $\mathrm{Ni}$ dots produced on $\mathrm{SiO}_{2}$ substrates.

The height of the Gaussian part of microstructures obtained by deducting $0.2 \mu \mathrm{m}$ from the total height was determined as a function of irradiation time, laser power and reactant pressure. The effect of irradiation time at various laser powers is illustrated in Fig. 3 . The linear increase in height with increasing laser power shows that the deposition rate is independent of

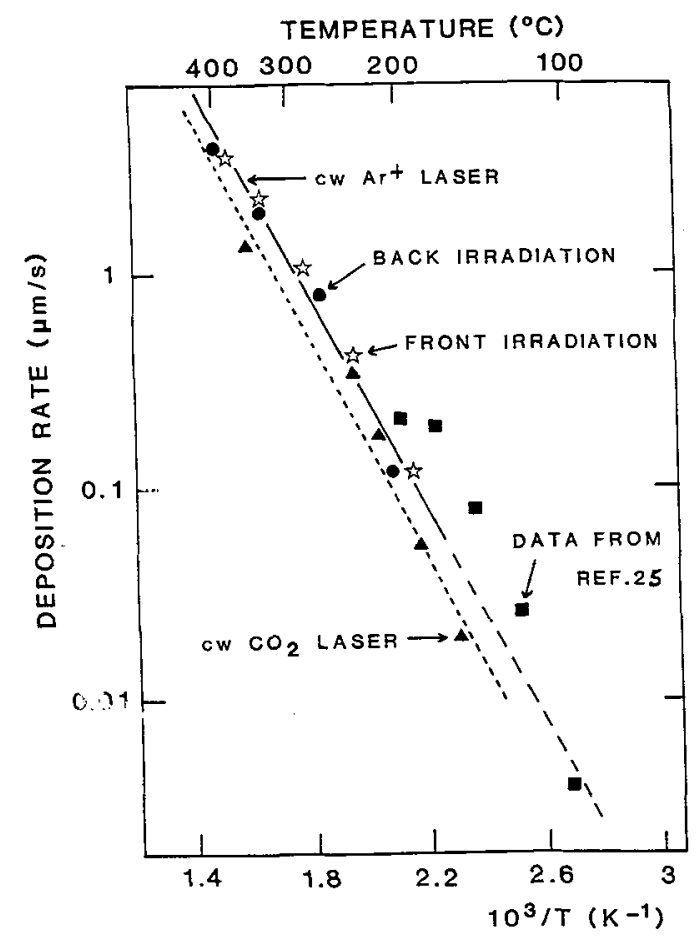

Fig.5 - Arrhenius diagram. 
irradiation time. The deposition rate deduced from the slope of curves given in Fig. 3 was found to increase exponentially as the laser power increased (Fig.4). In addition, the deposition rate was independent of $\mathrm{Ni}(\mathrm{CO})_{4}$ pressure. The kinetic data are represented in the Arrhenius diagram given in Fig.5; the apparent activation energy of the deposition process is equal to $12.0 \mathrm{kcal} \mathrm{mol}^{-1}$.

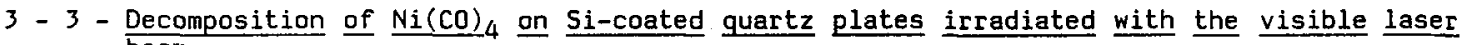
beam

The composition and structure of films deposited by scanning the laser beam over the substrate surface were investigated by Auger electron spectroscopy, nuclear reaction analyses and $X$-ray diffraction. The deposited material was determined to be polycrystalline nickel containing less than 0.5 at\% of carbon and oxygen.

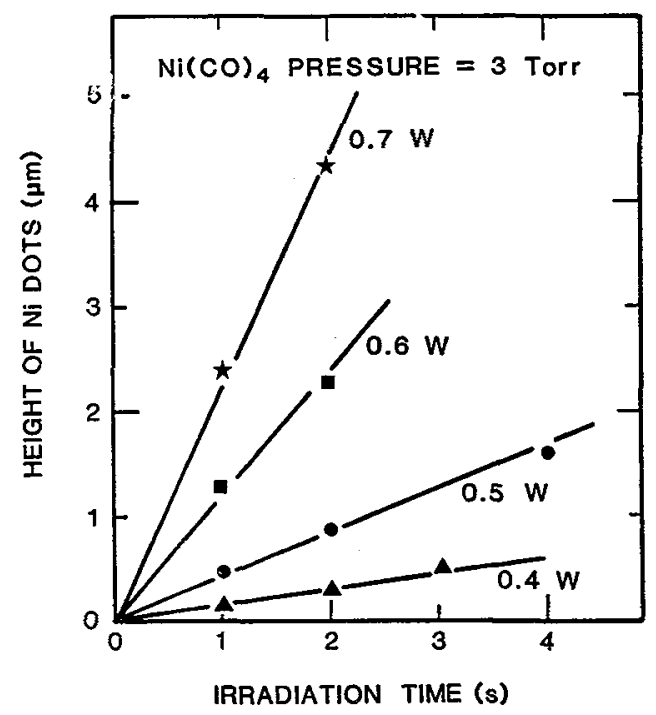

Fig.6 - Height of $\mathrm{Ni}$ dots versus irradiation time for various $\mathrm{cw} \mathrm{Ar}^{+}$laser powers.

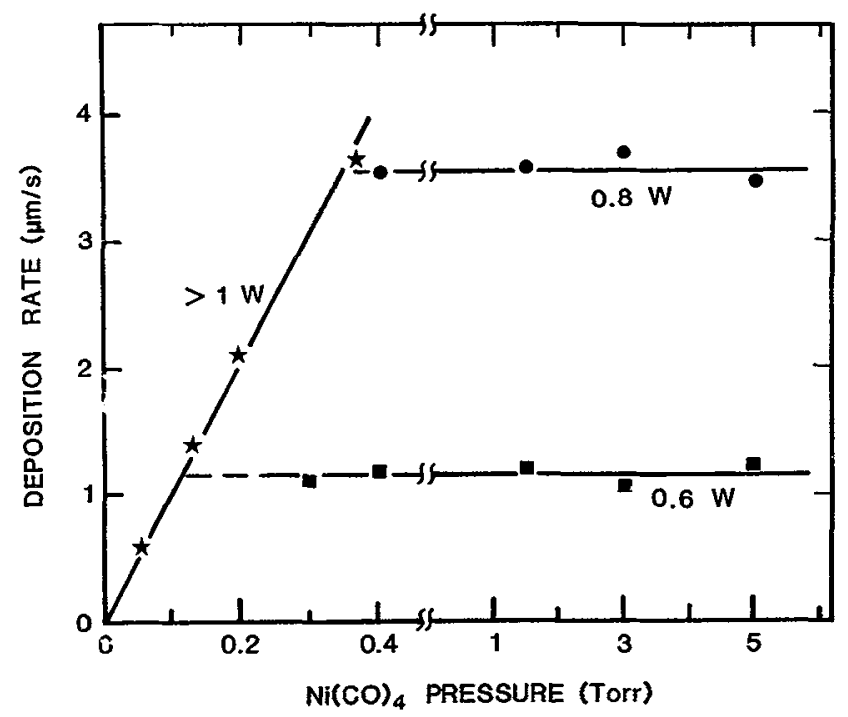

Fig.7 - $\left.\mathrm{Ni}_{(\mathrm{CO}}\right)_{4}$ pressure effect on deposition rate of $\mathrm{Ni}$ dots at various $\mathrm{cW} \mathrm{Ar}^{+}$laser powers. 
Nickel dots were deposited by laser irradiation of substrates in a fixed position for various irradiation times at a given laser power in the range of 0.2 to $1 \mathrm{~W}$. At high laser powers, dots with a Gaussian profile and flat-topped dots were deposited typically above and below 0.3 Tor of $\mathrm{Ni}(\mathrm{CO})_{4}$, respectively. The height of Gaussian $\mathrm{Ni}$ dots produced with a front irradiation of substrates at a $\mathrm{Ni}(\mathrm{CO})_{4}$ pressure of 3 Torr was found to be proportional to the irradiation time at various laser powers (Fig.6). The deposition rate of flat-topped dots produced at low reactant pressures and high laser powers or temperatures increased linearly as the reactant pressure was increased ( $\mathrm{Fig.7}$ ) and was independent of the laser power. Above 0.3 Torr, Gaussian $\mathrm{Ni}$ dots were produced with a deposition rate independent of the reactant pressure. Using the front or back laser irradiation of substrates, an exponential dependence of the deposition rate of Gaussian dots on the laser power was observed ( $F$ ig.8); however, at a given laser power, the deposition rate of $\mathrm{Ni}$ dots produced with the back irradiation was significantly higher than that of dots produced with the front laser irradiation. The dependence of the rate on the deposition temperature is illustrated in Fig.5. The kinetic data fit the Arrhenius law and the apparent activation energy is equal to 11.6 'kcal mol-1. Furthermore, at a given surface temperature, the deposition rate with the front irradiation of substrates is similar to the rate obtained with the back irradiation.

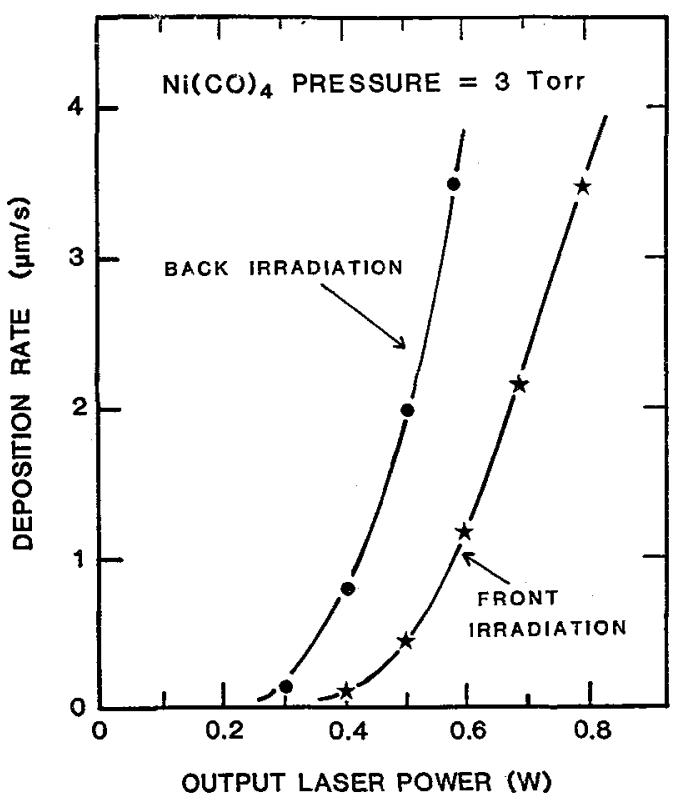

Fig.8 - $\mathrm{cw} \mathrm{Ar}{ }^{+}$laser power effect on deposition rate of $\mathrm{Ni}$ dots produced on $\mathrm{Si}$ substrates.

\author{
4 - DISCUSSION \\ $4-1$ - Decomposition of $\underline{W(\mathrm{CO})} 6$
}

The decomposition of $W(\mathrm{CO})_{6}$ is known to provide $W$ films slightly contaminated with $C$ and 0 atoms $/ 1,6 /$. In addition to the formation of $W$ and $C 0$ by dissociation of $W(\mathrm{CO}) 6$, several reactions can be expected to occur during the laser-induced process at elevated temperatures $\left(900^{\circ}-1300^{\circ} \mathrm{C}\right)$. Carbon monoxide can be dissociated at low temperatures to form carbon residues and $\mathrm{CO}_{2}$. The carbonaceous deposits surrounding the deposition zone may result from this dissociation. The formation of a small amount of tungsten carbide, $W_{2} C$ and $W C$, is also possible. Moreover, $W$ can interact with the $S i$ coating to give tungsten disilicide, WSi $i_{2}$. The formation of this compound by interdiffusion would lead to a reduction in height of the deposited dots due to volume contraction. However, since the oxygen content in the $5 i$ coating was relatively high (11 at\%) and the $\mathrm{Si}$ coating was covered with a native $\mathrm{SiO}_{2}$ layer, the formation of a significant amount of $\mathrm{WSi}_{2}$ is not very likely during very short irradiation times. The non linear dependence of the deposition rate on the deposition temperature in the range $900^{\circ}-1100^{\circ} \mathrm{C}$ suggests that the LCVD of microstructures does not involve a photolytic process. In this temperature range, the deposited material results probably from the thermodecomposition of $W(\mathrm{CO})_{6}$. Above $1100^{\circ} \mathrm{C}$, the non dependence of the deposition rate on the laser-induced surface temperature may be attributed to a limitation of the deposition kinetics by a mass-transport process. 
$4-2$ - Decomposition of $\mathrm{Ni}^{(\mathrm{CO})} 4$

Since the reactant gas, $\mathrm{Ni}(\mathrm{CO})_{4}$, is transparent at $10.59 \mu \mathrm{m}$, any photolytic effects of the laser beam on reactant molecules can be disregarded. Infrared photons serve essentially to heat the deposition area. At a laser power lower than $0.8 \mathrm{~W}$, the initial surface temperature of quartz substrates was high enough to initiate the decomposition of $\mathrm{Ni}(\mathrm{CO})_{4}$ molecules in the hot spot area (Fig.6); however, the surface reflectivity in the deposition area increased progressively as the metal thickness increased. As a result, the absorbed laser power into the substrate as well as the laser-induced surface temperature decreased with increasing $\mathrm{Ni}$ thickness. For $\mathrm{Ni}$ dots of $0.2 \mu \mathrm{m}$ in thickness and laser powers below $0.8 \mathrm{~W}$, the surface temperature was not sufficient for decomposition of reactant molecules. This decrease in deposition rate after deposition of $\mathrm{Ni}$ films with a certain thickness was already mentioned by Allen and coworkers /14/ for irradiation times as short as $400 \mathrm{~ms}$. This result suggests that the formation of the $0.2 \mu \mathrm{m}$ thick cylindrical dots is very fast and the time spent for deposition of the cylindrical base of microstructures deposited at laser powers higher than 0.8 W evaluated at $2 \mathrm{~ms}$ is negligible with respect to the overall irradiation times.

The data reported in Fig.5 show that the deposition rate of $\mathrm{Ni}$ dots was not modified by a direct irradiation of the reactive species (gas molecules and adsorbed species in the deposition area) with the photons emitted by the $\mathrm{cW} \mathrm{Ar}{ }^{+}$or $\mathrm{CO}_{2}$ laser. The kinetic data of these LCVD processes are in good agreement with those obtained for CVD of Ni films in furnace-type reactors $/ 25 /$. Consequently, a photolytic decomposition of $\mathrm{Ni}(\mathrm{CO})_{4}$ molecules can be disregarded and the LCVD of $\mathrm{Ni}$ dots is demonstrated to occur via a purely pyrolytic decomposition. of the reactant gas in the hot spot.

The growth kinetics of $\mathrm{Ni}$ layers produced by thermal decomposition of $\mathrm{Ni}(\mathrm{CO})_{4}$ in furnace-type CVD reactors has already been investigated $/ 25-27 \%$. The formation of $\mathrm{Ni}$ can proceed either via a homogeneous decomposition of $\mathrm{Ni}(\mathrm{CO})_{4}$ with an activation energy of $19.1 \mathrm{kcal}$ mol-1 or via a heterogeneous decomposition process with an activation energy of $14.3 \mathrm{kcal} \mathrm{mol}-1$. The experimental results reported by Carlton and oxley /25/ lie on the Arrhenius curve obtained for the LCVD process (Fig.5). Moreover, the growth rate of $\mathrm{Ni}$ films produced in furnace-type CVD reactors was found to be independent of reactant pressure /25,27/ as was the case for the LCVD of Gaussian $\mathrm{Ni}$ dots. This comparison between the LCVD and literature data shows clearly that the deposition kinetics of $\mathrm{Ni}$ dots is surface reaction controlled at reactant pressures ranging from 0.3 to 10 Torr. The decomposition of $\mathrm{Ni}(\mathrm{CO})_{4}$ molecules on the $\mathrm{Ni}$ surface involves schematically three successive elementary steps : (i) adsorption of $\mathrm{Ni}(\mathrm{CO})_{4}$ molecules on the $\mathrm{Ni}$ surface, (ii) decomposition of the adsorbed species on the surface, (iii) desorption of co molecules from the $\mathrm{Ni}$ surface. Several species such as $\mathrm{Ni}(\mathrm{CO})_{3}, \mathrm{Ni}(\mathrm{CO})_{2}$ and $\mathrm{NiCO}$ can exist in the adsorbed phase. $\mathrm{Ni}(\mathrm{CO})_{2}$ and $\mathrm{NiCO}$ were found to be the dominant adsorbed species in the formation of $\mathrm{Ni}(\mathrm{CO})_{4}$ from $\mathrm{Ni}$ and $\mathrm{CO} / 28,29 \%$. As a result, these species can reasonably be involved in the LCVD mechanism. Considering that $\mathrm{Ni}_{\text {s }}$ represents a $\mathrm{Ni}$ atom at the surface acting as an adsorption site and $\mathrm{Ni}_{c}$ is a Ni atom in the $\mathrm{Ni}$ crystal, the three successive steps of the reaction mechanism for the thermodecomposition of $\mathrm{Ni}(\mathrm{CO})_{4}$ under laser irradiation may be represented as follows :

$$
\begin{gathered}
\mathrm{Ni}(\mathrm{CO})_{4}(\mathrm{~g})+2 \mathrm{Ni}_{s} \underset{\mathrm{k}_{1}}{\stackrel{\mathrm{k}_{1}}{\rightleftarrows}} \mathrm{Ni} \mathrm{i}_{\mathrm{c}}+2 \mathrm{Ni}_{\mathrm{s}}(\mathrm{CO})_{2} \\
\mathrm{Ni}_{\mathrm{s}}(\mathrm{CO})_{2} \underset{\mathrm{k}_{2}}{\stackrel{\mathrm{k}_{2}}{\rightleftarrows}} \mathrm{Ni} \mathrm{i}_{\mathrm{s}} \mathrm{CO}+\mathrm{CO}(\mathrm{g}) \\
\mathrm{Ni}_{\mathrm{s}} \mathrm{CO} \underset{\mathrm{k}_{3}}{\stackrel{\mathrm{k}_{3}}{\rightleftarrows}} \mathrm{Ni}_{\mathrm{s}}+\mathrm{CO}(\mathrm{g})
\end{gathered}
$$

where $k$ and $k$ ' are the rate constants of the direct and reverse reactions, respectively; $k$ is the equilibrium constant of an elementary step $\left(K=k / k^{\prime}\right)$.

The concentrations of $\mathrm{Ni}_{s}, \mathrm{Ni}_{s} \mathrm{CO}$ and $\mathrm{Ni}_{s}(\mathrm{CO})_{2}$ can be calculated as functions of the total number of surface sites per $\mathrm{cm}^{2}$ and the fractions $\theta_{\mathrm{s}}, \theta_{1}$ and $\theta_{2}$ of the surface sites which are free and occupied by $\mathrm{CO}$ or $(\mathrm{CO})_{2}$, respectively. Furthermore, the rate of an elementary step which is proportional to the concentration of adsorbed species and $\mathrm{Ni}(\mathrm{CO})_{4}$ or $\mathrm{CO}$ partial pressure can be calculated as a function of $\theta_{5}, \theta_{1}, \theta_{2}$ and partial pressures of gases. At the quasi-steady state, the rate of the overall reaction is equal to the rate of the limiting step. In addition, since the rate constants of the other elementary steps are relatively high, the concentrations of species involved in these fast steps are linked by the equilibrium constant. As a result, the expression of the rate equation, $D_{R}$, can be established as a function of the $\mathrm{Ni}(\mathrm{CO})_{4}$ partial pressure, $P_{A}$, at a $\mathrm{CO}$ partial pressure of zero assuming that the rate limiting step is successively : 
- the dissociative adsorption of $\mathrm{Ni}(\mathrm{CO})_{4}$

$D_{R}=k_{1} P_{A}$

- the decomposition of $\mathrm{Ni}_{5}(\mathrm{CO})_{2}$

$D_{R}=\left[k_{2}\left(K_{1}\right)^{1 / 2} P_{A}^{1 / 2}\right] /\left[\left(k_{1}\right)^{1 / 2} P_{A}^{1 / 2}+1\right]$

- the desorption of $\mathrm{CO}$

$D_{R}=k_{3}$

In LCVD of Gaussian $\mathrm{Ni}$ dats, the actual partial pressure of CO was negligible and the deposition rate was independent of the $\mathrm{Ni}(\mathrm{CO})_{4}$ pressure. According to the rate laws given by Equs. (7) to (9), the rate limiting step of the deposition kinetics may be the desorption of co molecules from the $\mathrm{Ni}$ surface.

The deposition kinetics of flat-topped $\mathrm{Ni}$ dots produced below 0.3 Torr was probably not reaction surface limited since the deposition rate of these dots was independent of the deposition temperature. On the other hand, a gas diffusion limited process cannot be invoked because in this latter case, the deposition rate would decrease with increasing reactant pressure. In fact, the effects of deposition temperature and reactant pressure on the deposition rate suggest that the deposition kinetics was mass transport limited, i.e., the kinetics was limited by the number of $\mathrm{Ni}(\mathrm{CO})_{4}$ molecules colliding with the substrate surface. The ratio, flux of $\mathrm{Ni}(\mathrm{CO})_{4}$ molecules decomposed to flux of $\mathrm{Ni}(\mathrm{CO})_{4}$ molecules impinging on the surface, was calculated to be 0.62 and its value was independent of reactant pressure and deposition temperature. This ratio can be considered as the sticking coefficient of $\mathrm{Ni}(\mathrm{CO})_{4}$ molecules on the $\mathrm{Ni}$ surface. At reactant pressures lower than 0.3 Torr and at relatively elevated surface temperatures, the deposition kinetics is limited by the number of $\left.\mathrm{Ni}_{(\mathrm{CO}}\right)_{4}$ molecules able to stick on the $\mathrm{Ni}$ surface.

\section{5 - CONCLUSION}

The deposition kinetics of $\mathrm{W}$ and $\mathrm{Ni}$ microstructures produced by laser-induced decomposition of metal carbonyls was investigated as a function of irradiation time, reactant pressure and deposition temperature. The deposition of metal microstructures occurred by pyrolysis of metal carbonyls. The major drawback in the use of the laser-induced thermodecomposition of $W(C D)(f o r$ direct-write metallization of integrated circuits stems from the relatively low deposition rates of microstructures obtained even at very high temperatures (above $900^{\circ} \mathrm{C}$ ). The main limitation of the infrared laser-induced CVD of $\mathrm{Ni}$ microstructures from $\mathrm{Ni}(\mathrm{CO})_{4}$ arises from the high reflectivity of this metal which leads to a significant decrease in surface temperature and deposition rate at low laser powers; as a result, problems in reproducibility and control of the LCVD process can be expected. Finally, the deposition rate of Ni microstructures produced by visible laser-induced thermodecomposition of $\mathrm{Ni}(\mathrm{CO})_{4}$ which can $\mathrm{reach} 2 \mathrm{or} 3 \mu \mathrm{m} / \mathrm{s}$ below $400^{\circ} \mathrm{C}$ seems to fulfill the requirements of a metallization process by direct writing techniques. This LCVD process appears a promising candidate for use in the microelectronics industry.

\section{REFERENCES}

/1/ Lander, J.J. and Germer, L.H., Trans. Met. Soc. - AIME, 175 (1948) 648.

/2/ Carlton, H.E. and Goldberger, W.M., J. Metals, 17 (1965) 611 .

13/ Tsao, J.Y., Ehrlich, D.J., Silversmith, J. and Mountain, R.W., IEEE Elect. Dev. Lett., 3 (1982) 164.

14/ Osgood, R.M., Jr., Ann. Rev. Phys. Chem., 34 (1983) 77.

/5/ Ehrlich, D.J., Osgood, R.M., Jr. and Deutsch, T.F., J. Electrochem. Soc., 128 (1981) 2039.

16/ Gluck, N.S., Wolga, G.J., Bartosch, C.E., Ho, W. and Ying, Z., J. Appl. Phys., 61 (1987) 998.

/7/ Jackson, R.L. and Tyndall, G.W., J. Appl. Phys., 62 (1987) 315.

/8/ Solanki, R., Boyer, P.K., Mahan, J.E. and Collins, G.J., Appl. Phys. Lett., 38 (1981) 572.

19/ Solanki, R., Boyer, P.K. and Collins, G.J., Appl. Phys. Lett., 41 (1982) 1048.

/10/ Oprysko, M.M. and Beranek, M.W., J. Vac. Sci. Technol. B, 5 (1987) 496.

/11/ Allen, S.D., J. Appl. Phys., 52 (1981) 6501.

/12/ Allen, S.D., in "Physical Processes in Laser-Materials Interactions", edited by Bertolotti, M., (Plenum Press, New York, 1983), p.455.

/13/ Allen, S.D., Trigubo, A.B. and Jan, R.Y., in "Laser Diagnostics and Photochemical Processing for Semiconductor Devices", Mat. Res. Soc. Symp. Proc., edited by Osgood, R.M., Jr., Brueck, S.R.J, and Schlossberg, H.R., Vol.17, (North-Holland Publ., Amsterdam, 1983), p. 207.

/14/ Allen, S.D., Jan, R.Y., Mazuk, S.M. and Vernon, S.D., J. Appl. Phys., 58 (1985) 327. 
/15/ Baüerle, D., in "Lasez Diagnostics and Photochemical Processing for Semiconductor Devices", Mat. Res. Soc. Symp. Proc., edited by Osgood, R.M., Jr., Brueck, S.R.J. and Schlossberg, H.R., Vol.17, (North-Holland Publ., Amsterdam, 1983), p.19.

116/ Kräuter, W., Baüerle, D. and Fimberger, F., Appl. Phys. A, 31 (1983) 13.

/17/ Petzoldt, F., Piglmayer, K., Kraüter, W. and Baüerle, D., Appl. Phys. A, 35 (1984) 155.

118/ Bernhardt, A.F., Mc Williams, B.M., Mitlitsky, F. and Whitehead, J.C., in "Science and Technology of Microfabrication", Mat. Res. Soc. Symp. Proc., edited by Howard, R.E., Hu, E.L., Namba, S, and Pang, S., Vol.76, (Materials Research Society, Pittsburgh, PA, 1987), p. 223 .

19/ Herman, I.P., Hyde, R.A., Mc Williams, B.M., Weisberg, A.H. and Wood, L.L., in "Laser Diagnostics and Photochemical Processing for Semiconductor Devices", Mat. Res. Soc. Symp. Proc., edited by Osgood, R.M., Jr., Brueck, S.R.J. and Schlossberg, H.R., Vol.17, (North-Holland Publ., Amsterdam, 1983), p.9.

120/ Tonneau, D., Pauleau, Y. and Auvert, G., paper published in these proceedings.

$121 /$ Tonneau, D, and Auvert, G., in "Photon, Beam and Plasma-Enhanced Processing", Proceedings of the European Conference of the Materials Research Society, edited by Golanski, A., N'Guyen, V.T. and Krimmel, E.F., Vol. XV, (Editions de Physique, Paris, 1987), p.169.

122/ Tonneau, D. and Auvert, G., in "Laser and Particle-Beam Chemical Processing for Microelectronics", Mat. Res. Soc. Symp. Proc., edited by Ehrlich, D.J., Higashi, G.S. and Oprysko, M.M., Vol. 101, (Materials Research Society,Pittsburgh, PA, 1988), p.131.

123/ Tonneau, D., Ph. D Thesis, Université Joseph Fourier, Grenoble, France, (1988).

124/ "Handbook of Chemistry and Physics", 64th Edition, (CRC Press, Boca Raton, FL, 1983-1984).

/25/ Carlton, H.E, and Oxley, J.H., AIChE Journal, 13 (1967) 86.

/26/ Chan, R.K. and Mc Intosch, R., Can. J. Chem., $\frac{13}{40}$ (1962) 845.

/27/ Clements, P.J. and Sale, F.R., Metall. Trans. B, 7 (1976) 435.

/28/ O'Neill, C.E., Ph. D Thesis, Columbia University (1961), Dissert. Abstracts, 22 (1961) 1004.

129/ Trivin, H. Ph. D Thesis, University of Grenoble, France, (1973). 